\title{
Análise da Influência do Gás de Purga na Raiz de Juntas Soldadas pelo Processo GTAW em Aço Inoxidável Superduplex UNS S32750
}

\author{
(Analysis of the Influence of Backing Gas on the Root Joint Weld Using the GTAW Process on Superduplex Stainless Steel \\ UNS S32750)
}

\author{
Tobias Carvalho Campos Paival, Tabatta Regina de Brito Martins ${ }^{1}$, Guttemberg Chagas de Souza ${ }^{1}$, Juan Manuel Pardal', Sérgio \\ Souto Maior Tavares ${ }^{1}$, Maria Cindra Fonseca ${ }^{1}$ e Ismael Cardote Filho ${ }^{2}$ \\ ${ }^{1} U F F$ - Universidade Federal Fluminense/Departamento de Engenharia Mecânica / PGMEC / Pós-graduação em Montagem \\ Industrial-Niterói-RJ, Brasil-juanpardal@vm.uff.br \\ ${ }^{2}$ UTC Engenharia, Niterói - RJ, Brasil
}

\begin{abstract}
Resumo
Os aços inoxidáveis superduplex (AISD) são materiais que aliam altos valores de resistência mecânica com elevados níveis de resistência à corrosão. Por tal motivo, esta família de aços inoxidáveis é muito utilizada em componentes de processo na indústria offshore. No entanto, existem grandes desafios na soldagem destes materiais em termos de produtividade e custos mantendo-se a qualidade da junta produzida. Atualmente, a proteção gasosa da raiz é efetuada até o último passe de acabamento na soldagem durante a pré-montagem e montagem de tubulações de AISD em plataformas offshore. Neste tipo de proteção são usualmente empregados os gases hélio, argônio e nitrogênio, ou misturas destes. O nitrogênio é tipicamente adicionado no gás de proteção em teores de até $3 \%$ de modo a promover a estabilização da fase austenítica na superfície da raiz da solda. Devido ao alto custo do gás de proteção utilizado, é necessário determinar o passe ou camada na qual a proteção gasosa na raiz seja efetiva em termos das propriedades mecânicas e da resistência à corrosão, considerando ser esta uma região crítica, que ficará em contato com o fluido operante durante o serviço do componente. Neste sentido, o presente trabalho apresenta os resultados da influência da utilização de gás de purga na raiz de juntas soldadas correspondente a uma tubulação de aço inoxidável superduplex (AISD) UNS S32750 de $9 \mathrm{~mm}$ de espessura de parede soldada pelo processo de soldagem TIG (GTAW). Foram avaliados o ciclo térmico, o teor de nitrogênio e a tenacidade ao impacto da raiz da solda em função do aporte térmico para diversas juntas soldadas com diferentes nivveis de proteção gasosa na raiz. Deste modo, o presente trabalho tem como objetivo a redução de custos na soldagem de tubulações indicando até qual camada é requerida a proteção gasosa na raiz em função do aporte de calor empregado.
\end{abstract}

Palavras-chave: Aços Inoxidáveis Superduplex; Soldagem GTAW; Gás de Purga; Aporte de Calor.

\begin{abstract}
Superduplex stainless steels (SDSS) are materials that have high mechanical strength and corrosion resistance and, for this reason, they are widely used in components for the offshore industry. Despite this, there are great challenges in the welding process of this material in relation to productivity and costs whilst maintaining the high quality of the weld produced. In reality, during the preassembly and assembly of SDSS pipelines at offshore platforms, backing gas protection of the root is executed until the last pass of the welding procedure. The most common gases used are helium, argon and nitrogen, or a mixture of these. Up to 3\% of nitrogen is typically added to the mix to promote the stabilization of austenitic phase at the welding root surface. Due to the high cost of the protection gas, there is a market need to determine the pass or layer in which the root backing gas protection is effective, in terms of the mechanical properties and the corrosion resistance, because the region will be in constant contact with the fluid during the component service life. This work presents the results of the influence of the utilization of backing gas on the root of welded joints of superduplex stainless steel (SDSS) UNS S32750 piping, with a thickness of $9 \mathrm{~mm}$, welded by the gas tungsten arc welding (GTAW) process. The thermal cycle, nitrogen content and the toughness of the welding root were evaluated in function of the heat input for various samples with different levels of backing gas protection on the root. The primary objectives of this work are; the reduction of costs of the welding process of pipes and to show which layer requires backing gas protection on the root in function of the heat input.
\end{abstract}

Key-words: Superduplex Stainless Steel; Welding, GTAW; Backing Gas; Heat Input.

\section{Introdução}

Recebido em 07/03/2014, texto final em 23/04/2014.

DOI: 10.1590/0104-9224/SI1902.04
Os aços inoxidáveis duplex (AID) e superduplex (AISD) são materiais com microestrutura bifásica, compostos por ferrita $(\delta)$ e austenita $(\gamma)$ em proporções semelhantes. Estes materiais 
se caracterizam por apresentarem excepcional combinação de propriedades mecânicas, aliada a uma excelente resistência à corrosão sob condições críticas de trabalho, o que os torna uma alternativa disponível em relação aos aços inoxidáveis austeníticos convencionais. Os AISD se distinguem dos AID por possuírem um maior valor do índice equivalente de resistência ao pite (PRE) dependente dos teores de cromo $(\mathrm{Cr})$, molibdênio (Mo), tungstênio $(\mathrm{W})$ e nitrogênio $(\mathrm{N})$ presentes na liga. $\mathrm{O}$ balanço microestrutural pode ser conseguido pela adição controlada destes elementos de liga com especial ênfase nas proporções de $\mathrm{Cr}$ e níquel (Ni). Deste modo, a concentração destes elementos é ajustada usando o diagrama de equilíbrio ternário $\mathrm{Fe}-\mathrm{Ni}-\mathrm{Cr}$, visando obter uma microestrutura em partes aproximadamente semelhantes de ferrita e austenita [1].

No entanto, é importante ressaltar que durante a soldagem do AISD deve-se manter a microestrutura bifásica do metal de solda (MS) que deverá conter entre 30 a $70 \%$ de ferrita $(\delta)$, além de evitar a precipitação de fases deletérias tal como a fase sigma $(\sigma)$ e nitretos de cromo $\left(\mathrm{Cr}_{2} \mathrm{~N}\right)$ na fase $\delta$ [2]. De modo a contemplar estes fatos, recomenda-se que o aporte de calor esteja compreendido entre 0,3 e $1,5 \mathrm{~kJ} / \mathrm{mm}$ e a temperatura interpasse abaixo dos $100^{\circ} \mathrm{C}[3]$.

$\mathrm{O}$ nitrogênio é adicionado em ligas de AID e AISD para estabilizar a austenita $(\gamma)$ aumentando a resistência mecânica e à corrosão. Como mostrado na Figura 1, a solubilidade do nitrogênio é maior na austenita do que na ferrita, em temperaturas abaixo de $1250^{\circ} \mathrm{C}$. A mudança brusca do limite de solubilidade na fase ferrita é motivo pelo qual se restringe o valor inferior do aporte de calor com o intuito de não promover uma grande velocidade de resfriamento e, consequentemente dar origem à formação de $\mathrm{Cr}_{2} \mathrm{~N}$ nesta fase.

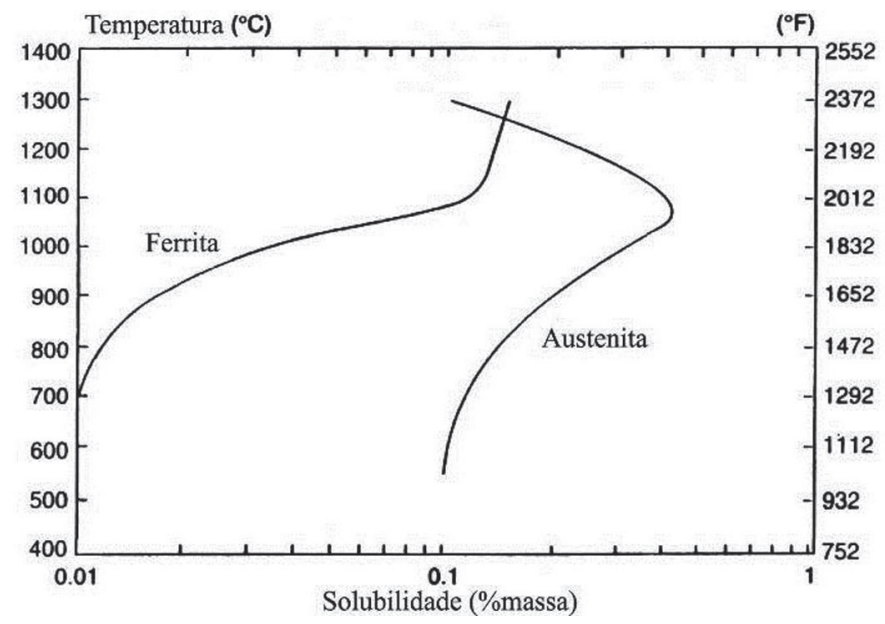

Figura 1. Solubilidade do nitrogênio na ferrita e na austenita

[4].

O processo GTAW é um dos mais utilizados na soldagem de aços AID e AISD, sendo geralmente adotado para os passes de raiz em soldas multipasses. Uma das recomendações, além da adição de 1 a $3 \%$ nitrogênio ao gás de proteção, é a proteção da raiz da solda com gás de purga, para evitar oxidação. Após a solda, para uma melhor resistência à corrosão, é também recomendada a realização de uma passivação decapante em pasta ou solução a base de $\mathrm{HNO}_{3}$ com pequenas adições de $\mathrm{HF}$ [5].

Atualmente, nos empreendimentos da indústria brasileira, a soldagem de tubulações de AID e AISD pelo processo GTAW é realizada com proteção de purga gasosa na raiz até o último passe de acabamento de modo que o teor de oxigênio não exceda o valor de $0,5 \%$. Neste sentido, é muito frequente a utilização de $100 \%$ nitrogênio como gás de purga devido ao menor custo, se comparado aos gases inertes argônio (Ar) e hélio (He). No entanto, na soldagem multipasse, para garantir a temperatura interpasse, o tempo de arco aberto é consideravelmente grande, o que provoca um elevado consumo de gás de purga durante todo o processo se tornando oneroso para tubulações de grande espessura. Deste modo, existe uma necessidade de mercado na determinação do passe ou camada, na qual a proteção gasosa na raiz seja efetiva em termos das propriedades mecânicas e da resistência à corrosão, considerando ser esta uma região crítica, que ficará em contato com o fluido operante durante o serviço do componente. Neste sentido, o presente trabalho apresenta os resultados da influência da utilização de gás de purga na raiz de juntas soldadas correspondente a uma tubulação de aço inoxidável superduplex (AISD) UNS S32750 de $9 \mathrm{~mm}$ de espessura de parede soldada pelo processo de soldagem TIG $(G T A W)$. Foram avaliados o ciclo térmico, o teor de nitrogênio e a tenacidade da raiz da solda, em função do aporte de calor para diversas juntas obtidas com diferentes níveis de proteção gasosa na raiz. Entende-se por diferentes níveis de proteção até qual camada é mantida a proteção gasosa na raiz. Deste modo, o presente trabalho tem como objetivo a redução de custos na soldagem de tubulações desta classe de materiais indicando até qual camada é requerida a proteção gasosa em função do aporte de calor empregado na soldagem.

\section{Materiais e Métodos}

O material do metal de base (MB) utilizado no estudo foi um AISD UNS S32750, na forma de tubo, com 254,0 mm de diâmetro e 9,3 $\mathrm{mm}$ de espessura de parede, fabricado de acordo com a norma ASTM A928 Classe 1 encontrando-se no estado solubilizado. O metal de adição (MA) utilizado na soldagem GTAW foi vareta de AISD da marca comercial Sandvik 25.10.4L conforme AWS ER 2594 com bitola de 3,2mm de diâmetro. As Tabelas 1 e 2 apresentam, de forma respectiva, as propriedades mecânicas e composições químicas do material do MB e do MA utilizados de acordo com o certificado dos fabricantes.

A soldagem foi efetuada em dois tubos, denominados T-01 e T-02, na posição $6 \mathrm{G}$, pelo processo $G T A W$, com polaridade direta (CC-) empregando um eletrodo não consumível de tungstênio com $2 \%$ de tório (EW-Th2), com 3,2 mm de diâmetro e temperatura interpasse menor que $100^{\circ} \mathrm{C}$. Durante o processo de soldagem foi utilizado como gás de proteção na tocha uma mistura contendo $97,5 \% \mathrm{Ar}+2,5 \% \mathrm{~N}_{2}$, com vazão de $15,5 \ell /$ minuto. A proteção de purga na raiz foi realizada com gás nitrogênio contendo $99,9 \%$ e vazão de $10 \ell / \mathrm{min}$. A proteção da raiz foi avaliada através da medição do teor de oxigênio no interior da tubulação por meio de oxímetro, para que o teor de oxigênio não excedesse a $0,5 \% \mathrm{em}$ peso. A geometria e dimensões das juntas estudadas são apresentadas na Figura 2. 
Tabela 1. Propriedades mecânicas do AISD e do metal de adição*.

\begin{tabular}{|c|c|c|c|}
\hline Material & $\boldsymbol{\sigma}_{\mathrm{LE} \text { min }}(\mathbf{M P a})$ & $\boldsymbol{\sigma}_{\mathrm{LR} \min }(\mathbf{M P a})$ & Alongamento (\%) \\
\hline Metal de Base (MB) & 550 & 800 & 25 \\
\hline Metal de Adição (MA) & 650 & 850 & 25 \\
\hline
\end{tabular}

* Os valores de dureza, das tensões limites de escoamento mínimo $\left(\sigma_{\mathrm{LE} \text { min }}\right)$ e de resistência à ruptura mínima $\left(\sigma_{\mathrm{LR} \text { min }}\right)$ e o correspondente alongamento (\%) em 50,8 $\mathrm{mm}$ foram obtidos na temperatura ambiente.

Tabela 2. Composição química do MB e MA utilizados.

\begin{tabular}{|c|c|c|c|c|c|c|c|c|c|c|c|}
\hline \multirow{2}{*}{ Material } & \multirow{2}{*}{ Classificação } & \multicolumn{8}{|c|}{ Composição química (\% em peso). Fe balanço. } & \multirow{2}{*}{ PRE } \\
\cline { 3 - 12 } & & $\mathbf{C r}$ & $\mathbf{N i}$ & $\mathbf{M o}$ & $\mathbf{M n}$ & $\mathbf{S i}$ & $\mathbf{N}$ & $\mathbf{C}$ & $\mathbf{P}$ & S & \\
\hline MB & UNS S32750 & 24,700 & 6,900 & 3,800 & 0,770 & 0,230 & 0,280 & 0,010 & 0,022 & 0,001 & $\mathbf{4 1 , 7 2 0}$ \\
\hline MA & ER 2594 & 25,000 & 9,500 & 4,000 & 0,400 & 0,300 & 0,240 & $<0,020$ & $<0,020$ & $<0,015$ & $\mathbf{4 1 , 5 4 0}$ \\
\hline
\end{tabular}

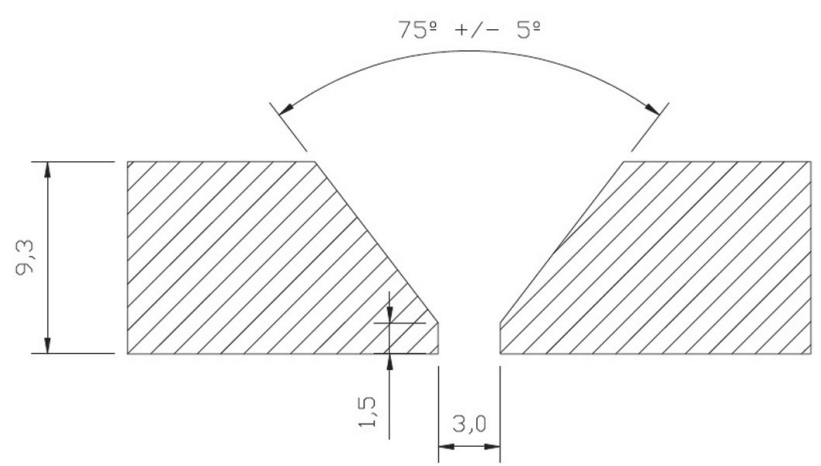

Figura 2. Características dimensionais e geométricas do chanfro da junta da tubulação.

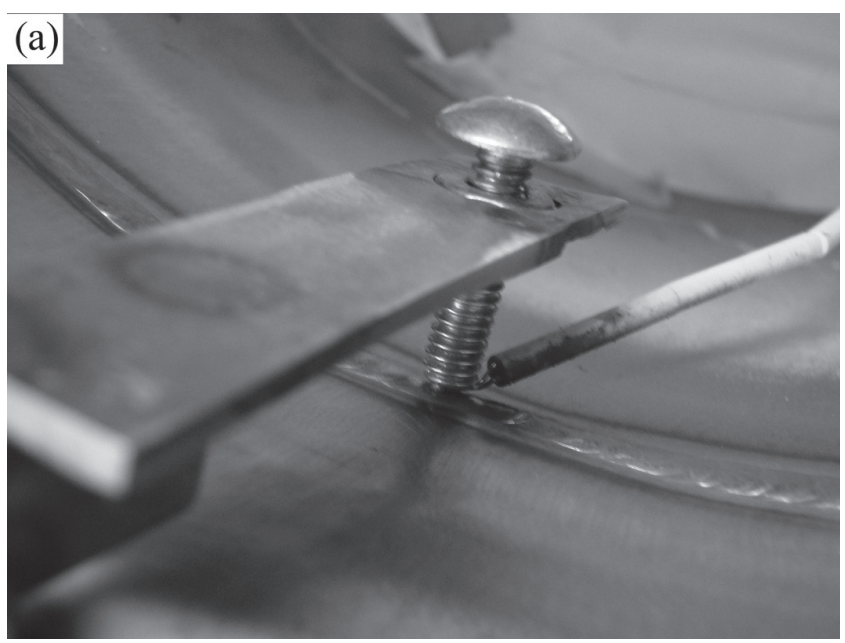

Foram produzidas oito (8) amostras pela soldagem de uma junta circunferencial, sendo cada uma das amostras equivalente a um quarto da seção circular do tubo soldado. Do tubo identificado como T-01 foram obtidas as amostras 1 a 4 (A1-4) e de T-02 foram obtidas as amostras 5 a 8 (A5-8). Com o intuito de monitorar o ciclo térmico na raiz da junta de cada amostra, foram instalados termopares Pt-Rh nas faces internas de cada raiz produzida, conectados a um registrador de temperatura. A Figura 3 mostra o esquema de montagem do termopar na raiz da solda. Os tubos foram soldados utilizando diferentes aportes de calor e níveis de proteção de gás de purga conforme apresentado e indicado na Tabela 3. As Figuras 4 e 5 exibem a quantidade de passes e camadas obtidas em cada amostra.

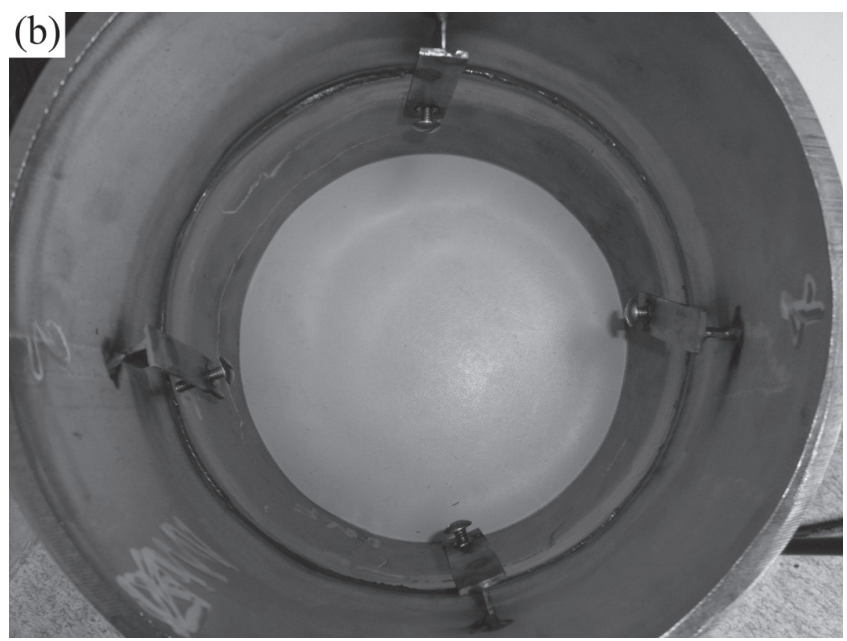

Figura 3. (a) Fixação do termopar na face da raiz previamente produzida. (b) Vista geral da montagem dos termopares.

Tabela 3. Nível de proteção do gás de purga e aporte de calor em cada amostra.

\begin{tabular}{|c|c|c|}
\hline Amostra & Nível de proteção com Gás de Purga & Aporte de Calor Médio (kJ/mm) \\
\hline $\mathbf{1}$ & $1^{\mathrm{a}}$ Camada (Raiz) & 0,5 \\
\hline $\mathbf{2}$ & $1^{\mathrm{a}}$ e $2^{\mathrm{a}}$ Camadas (Raiz e reforço) & 0,5 \\
\hline $\mathbf{3}$ & $1^{\mathrm{a}}, 2^{\mathrm{a}} \mathrm{e} 3^{\mathrm{a}}$ Camadas & 0,5 \\
\hline $\mathbf{4}$ & $1^{\mathrm{a}}, 2^{\mathrm{a}}, 3^{\mathrm{a}} \mathrm{e} 4^{\mathrm{a}} \mathrm{e} 5^{\mathrm{a}}$ Camadas (Total) & 0,5 \\
\hline $\mathbf{5}$ & $1^{\mathrm{a}}$ Camada (Raiz) & 1,5 \\
\hline $\mathbf{6}$ & $1^{\mathrm{a}} \mathrm{e} 2^{\mathrm{a}}$ Camadas (Raiz e reforço) & 1,5 \\
\hline $\mathbf{7}$ & $1^{\mathrm{a}}, 2^{\mathrm{a}}$ e $3^{\mathrm{a}}$ Camadas & 1,5 \\
\hline $\mathbf{8}$ & $1^{\mathrm{a}}, 2^{\mathrm{a}}, 3^{\mathrm{a}} \mathrm{e} 4^{\mathrm{a}}$ Camadas (Total) & 1,5 \\
\hline
\end{tabular}




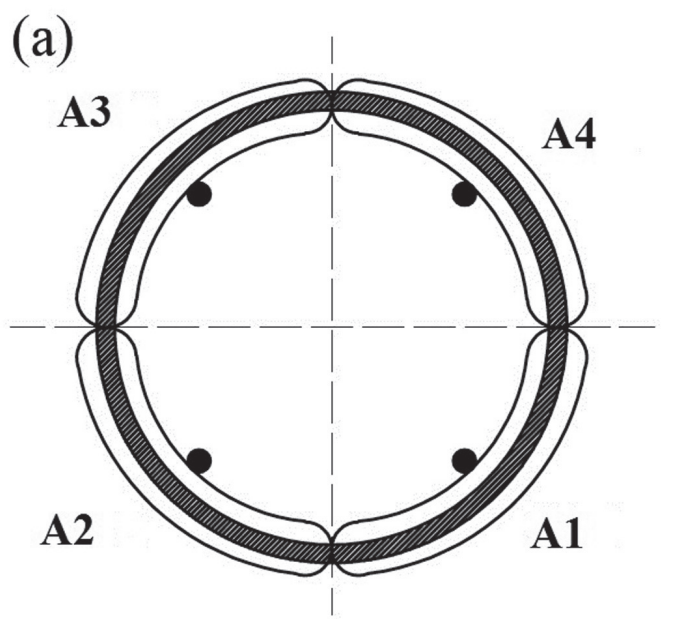

- Termopar

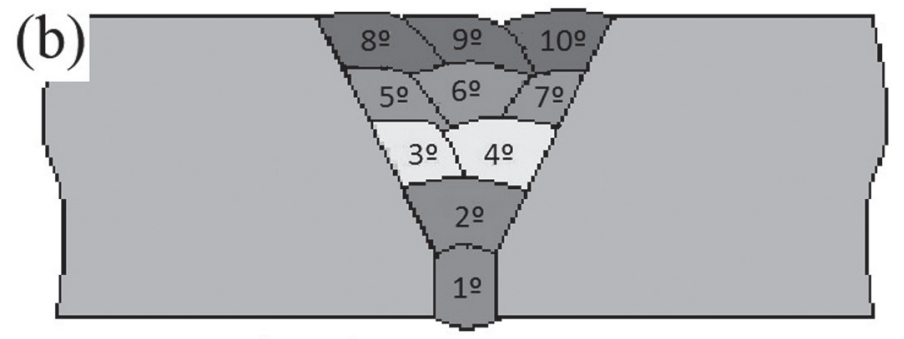

Legenda:

1․ camada (1ㅇp passe)

2a camada (2 passe)

3a camada (3ㅇ e 4 passes)

4ㅇ camada (5, 60 e 7ㅇ passes)

5a camada ( $8 \circ, 9 \circ$ e 10 passes)

Figura 4. T-01 - (a) Desenho esquemático das amostras de 1 a 4. (b) Número de passes com aporte de calor de 0,5 kJ/mm.

(a)

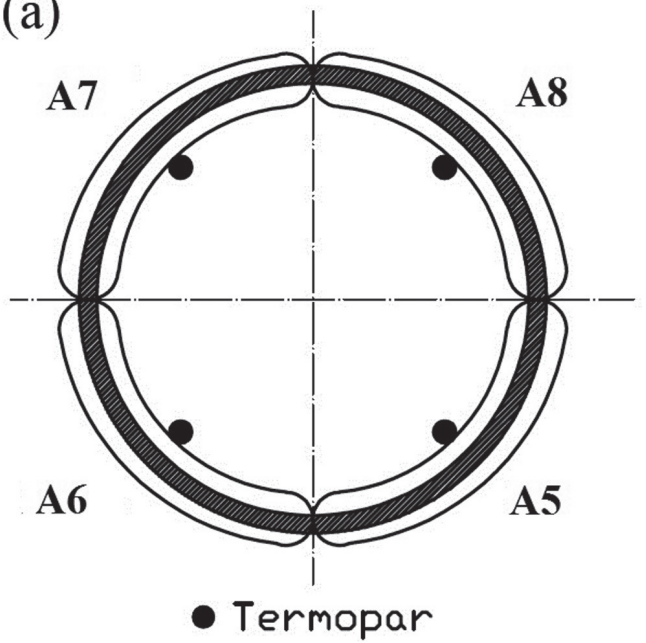

(b)

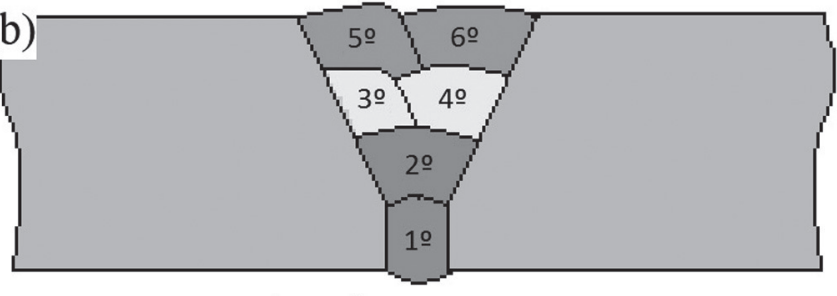

Legenda:

1 a camada (10 passe)

2a camada ( 20 passe)

3a camada ( 3 e 4 으 passes)

4 a camada (5ㅇ e 6으 passes)

Figura 5. T-02 - (a) Desenho esquemático das amostras de 5 a 8. (b) Número de passes com aporte de calor de 1,5 kJ/mm.

(a)

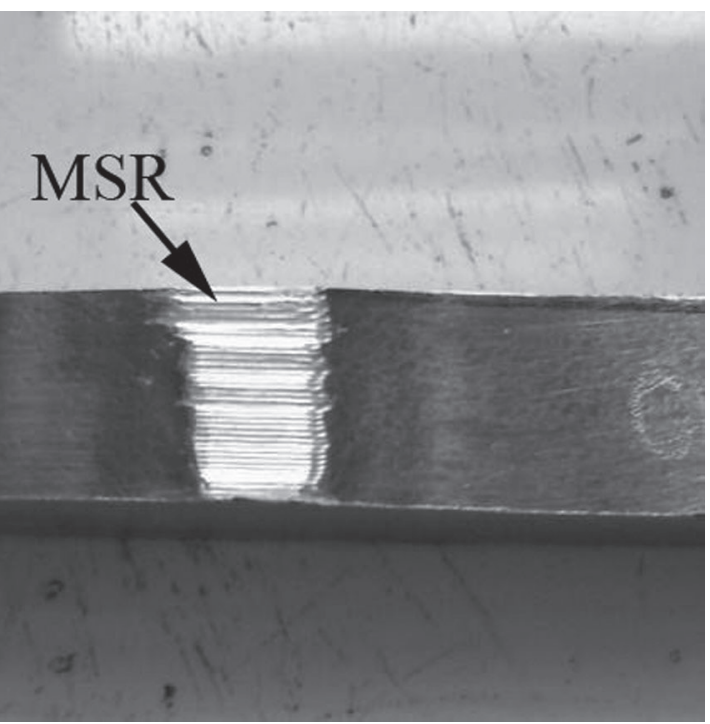

(b)
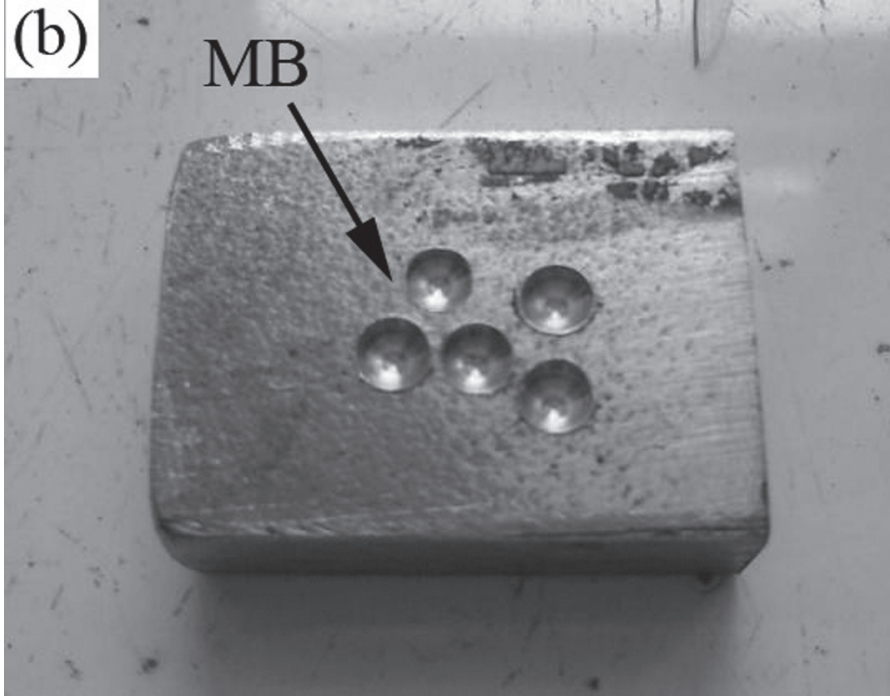

Figura 6. Esquema do local de retirada de cavaco para determinação do teor de nitrogênio. (a) MSR. (b) MB. 



Figura 7. Cps da raiz e enchimento (a) Com entalhe no CS. (b) Com entalhe na ZTA.

A análise metalográfica foi realizada utilizando um microscópio ótico, avaliando-se as microestruturas do MB e da raiz da junta. O reagente Beraha foi utilizado, para revelar e quantificar as proporções de $\delta$ e $\gamma$. As quantificações foram realizadas através de uso do software específico Image Tools v.3.0 [6], com média de 12 imagens por região feitas com diferentes aumentos metalográficos.

$\mathrm{O}$ teor de nitrogênio foi avaliado por combustão, via instrumental, no metal de base (MB) e na raiz da junta das amostras que tiveram proteção gasosa parcial (A1-3 e A5-7). A análise foi feita mediante a retirada de $1 \mathrm{~g}$ de cavaco do $\mathrm{MB}$ com o uso de uma furadeira. Para o metal de solda da raiz (MSR), foi retirado $1 \mathrm{~g}$ de cavaco da superfície externa desta utilizando uma plaina limadora, com mínima profundidade de corte. As regiões de retirada do cavaco estão mostradas na Figura 6.

Para a realização do ensaio de impacto, foram ensaiados 80 corpos de prova (cps) de tamanho reduzido, $55 \mathrm{~mm}$ x $10 \mathrm{~mm}$ x $2,5 \mathrm{~mm}$, com entalhe tipo "V" à temperatura de $-46^{\circ} \mathrm{C}$ [7]. Os cps foram retirados perpendicularmente à junta soldada o mais próximo à superfície da raiz e do enchimento, como mostra a Figura 7. O entalhe foi feito no centro do metal de solda (CS) e a 2,0mm da linha de fusão na direção da ZTA, totalizando $6 \mathrm{cps}$ do CS e ZTA da raiz e 4 para o enchimento no CS e ZTA, para cada condição de soldagem.

\section{Resultados e Discussão}

A Figura 8 mostra a média das temperaturas máximas alcançadas por camada para as amostras do T-01 e T-02. Devido ao menor aporte de calor a temperatura máxima atingida foi menor no T-01 se comparada ao T-02. No entanto, as temperaturas máximas atingidas, devido ao passe de reforço, em ambos os casos, se encontram acima da temperatura considerada como crítica de $800^{\circ} \mathrm{C}$, tendo em consideração que acima deste valor há uma considerável variação do limite de solubilidade do nitrogênio na fase austenita, conforme mostrado na Figura 1. Durante o processo de soldagem, as temperaturas medidas na raiz ficaram abaixo de $700^{\circ} \mathrm{C}$ na terceira camada para o T-01 e na quarta camada, para o T-02. Este fato resulta interessante já que, abaixo desta temperatura, não há mudanças significativas do limite de solubilidade de nitrogênio na austenita.

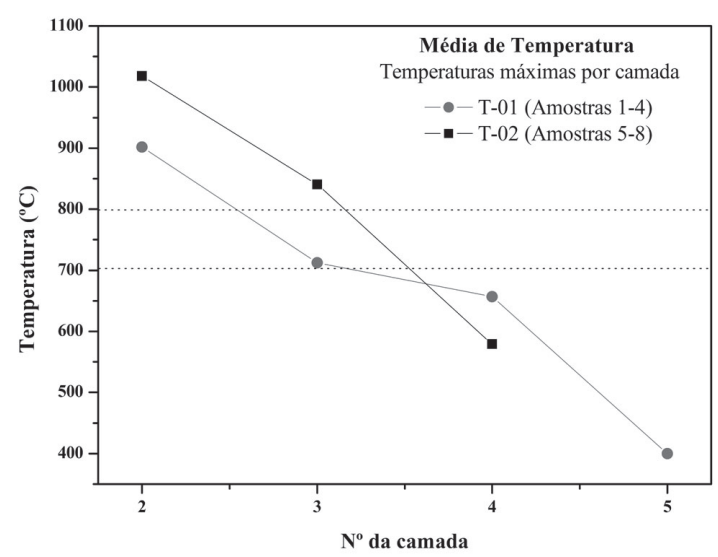

Figura 8. Média das temperaturas máximas atingidas por camada para T-01 e T-02.

A Figura 9 apresenta, exemplificativamente para a amostra 2 (A2), os ciclos térmicos de determinados passes para cada camada, evidenciando o tempo de permanência acima da temperatura considerada como crítica de $800^{\circ} \mathrm{C}$. Neste caso, somente o passe de reforço ultrapassou a temperatura crítica. Entretanto, na Tabela 4 são apresentados os valores de tempo acima de $800^{\circ} \mathrm{C}$ de cada amostra, acrescentando nesta o tempo total em que raiz ficou exposta acima dos $800^{\circ} \mathrm{C}$ para os sucessivos passes. É interessante frisar que nas soldagens com maior aporte de calor $(1,5 \mathrm{~kJ} / \mathrm{mm})$ os tempos de permanecia acumulados, acima de $800^{\circ} \mathrm{C}$ na raiz, foram superiores aos das amostras produzidas com menor aporte de calor $(0,5 \mathrm{~kJ} / \mathrm{mm})$.

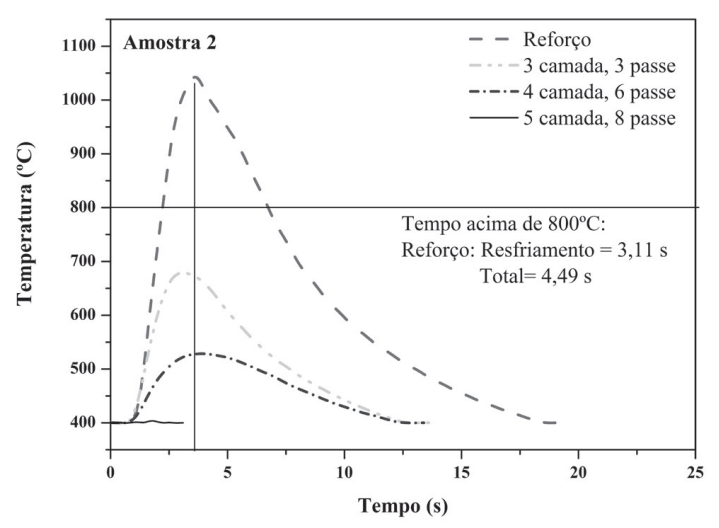

Figura 9. Ciclos térmicos para a amostra 2. 
Tabela 4. Tempo de permanência acima de $800^{\circ} \mathrm{C}$ em cada camada.

\begin{tabular}{|c|c|c|c|}
\hline \multicolumn{4}{|c|}{ Tempo de Permanência acima de $800^{\circ} \mathrm{C}(\mathrm{s})$} \\
\hline Amostra & Reforço & $3^{\text {a }}$ Camada & Total Geral \\
\hline A1 & 3,76 & --------- & 3,76 \\
\hline A2 & 4,49 & --------- & 4,49 \\
\hline A3 & --------- & -------- & --------- \\
\hline A4 & 3,69 & 0,79 & 4,48 \\
\hline A5 & 10,18 & 6,58 & 16,76 \\
\hline A6 & 10,11 & --------- & 10,11 \\
\hline A7 & 10,77 & 2,46 & 13,23 \\
\hline A8 & 11,42 & 12,91 & 24,33 \\
\hline
\end{tabular}

A Tabela 5 apresenta o resultado da análise da composição química por combustão para análise do teor de nitrogênio na raiz das condições em que a proteção gasosa na purga de raiz foi totalmente ou parcialmente removida (amostras 1-3 e amostras 5-7). Conforme se observa nesta tabela, o teor de nitrogênio contido em solução sólida na raiz possui valores crescentes na medida em que a proteção gasosa na purga for mantida. Embora, já nas amostras 2 e 6 , com proteção até a segunda camada, os valores de nitrogênio contidos estão entre 91 e $96 \%$ daquele levantado para o MB. Pode-se ainda verificar que a partir da proteção na terceira camada inclusive, das amostras 3 e 7, os valores são quase semelhantes ao MB. Esta análise é de grande interesse tendo em vista que o valor do índice equivalente de resistência ao pite $(P R E)$ depende em sobremaneira da presença deste elemento, além da região da raiz ser aquela que fica em contato com o fluido de processo.

A Figura 10 mostra a microestrutura característica do metal de base, atacada com o reagente Beraha. $\mathrm{O}$ ataque revela

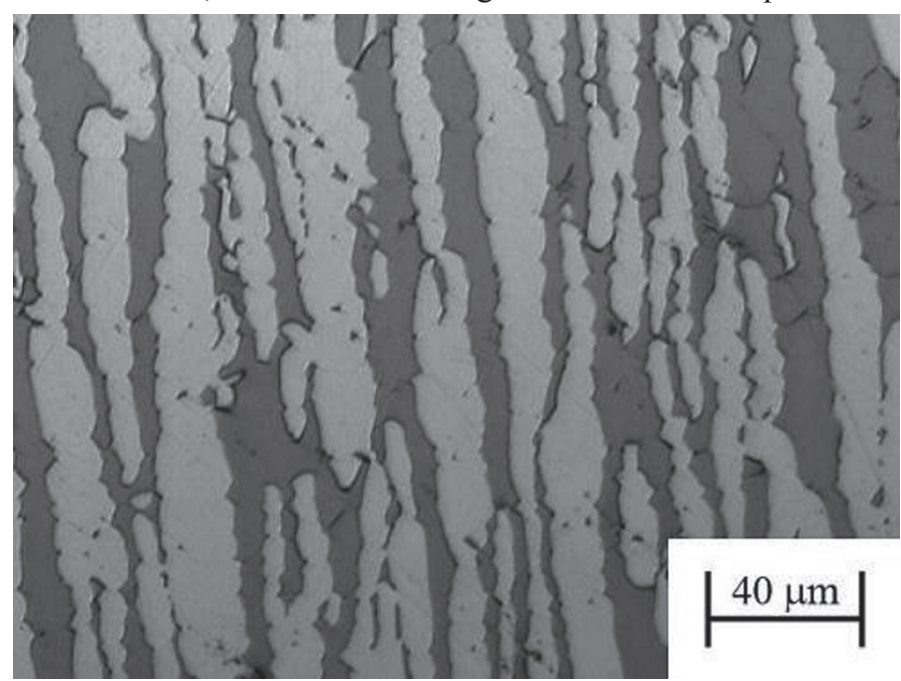

Figura 10. Microestrutura do metal de base (MB). uma boa distinção entre as fases ferritica $\delta$ (fase escura) e austenitica $\gamma$ (fase clara), onde a proporção da fase ferrita foi de aproximadamente $46,69 \pm 1,90 \%$.

As Figuras 11 a 18 exibem as microestruturas características da raiz do metal de solda(MS) das amostras 1 a 8 , respectivamente, com um aumento aproximado de 950X enquanto a Tabela 6 apresenta os resultados da quantificação de fases, ferrita $(\delta)$ e austenita $(\gamma)$ na raiz da junta soldada assim como no metal de base. Os resultados exibem valores de proporção de fases próximos entre a ferrita e a austenita assim como apresentado para o $\mathrm{MB}$, não havendo influência significativa do aporte de calor e do nível de proteção gasosa na raiz.

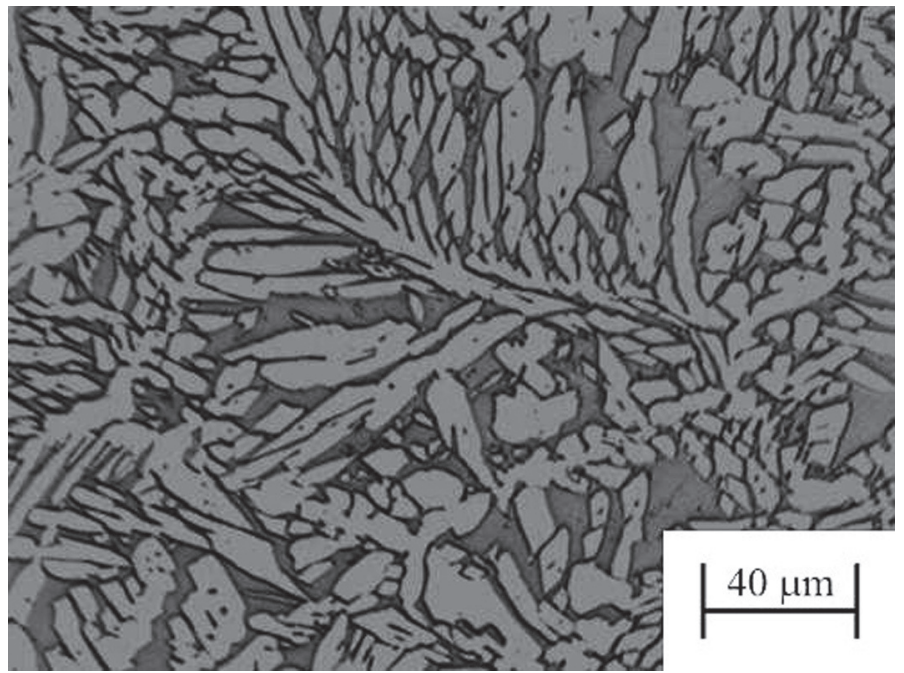

Figura 11. Microestrutura do MS na raiz da junta. Amostra 1.

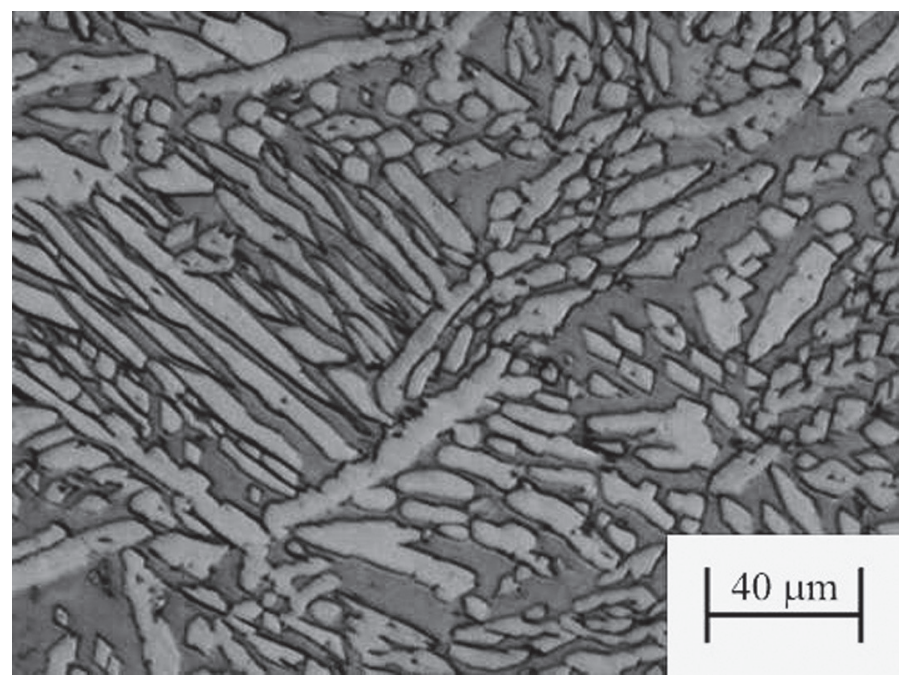

Figura 12. Microestrutura do MS na raiz da junta. Amostra 2.

Tabela 5. Teor de nitrogênio da raiz.

\begin{tabular}{|c|c|c|c|c|c|c|c|}
\hline Amostra & $\mathbf{A 1}$ & $\mathbf{A 2}$ & $\mathbf{A 3}$ & $\mathbf{A 5}$ & $\mathbf{A 6}$ & $\mathbf{A 7}$ & MB \\
\hline $\mathbf{\% N}$ & 0,199 & 0,234 & 0,240 & 0,222 & 0,226 & 0,239 & 0,244 \\
\hline
\end{tabular}




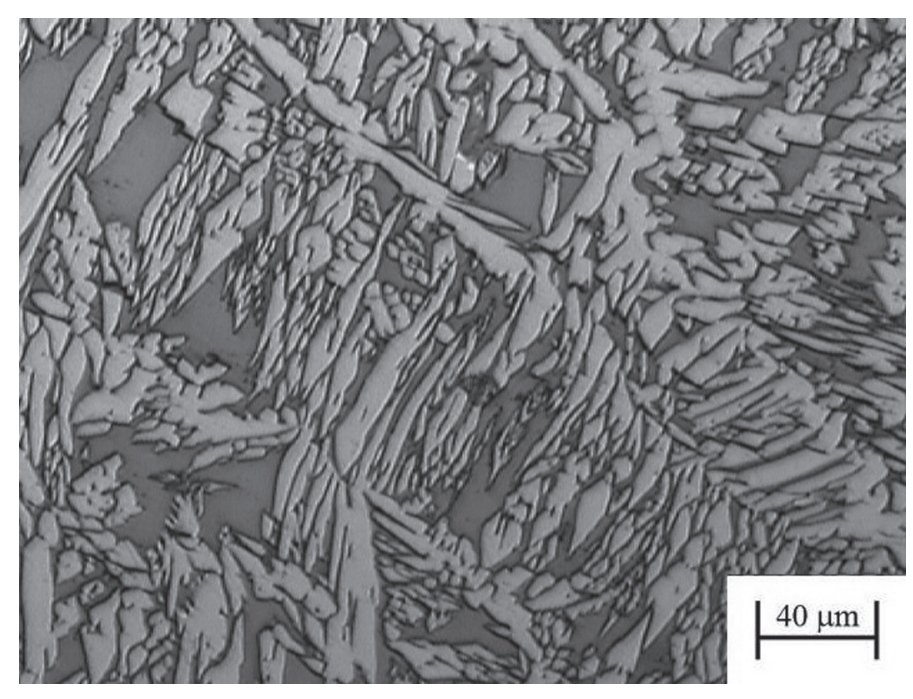

Figura 13. Microestrutura do MS na raiz da junta. Amostra 3.

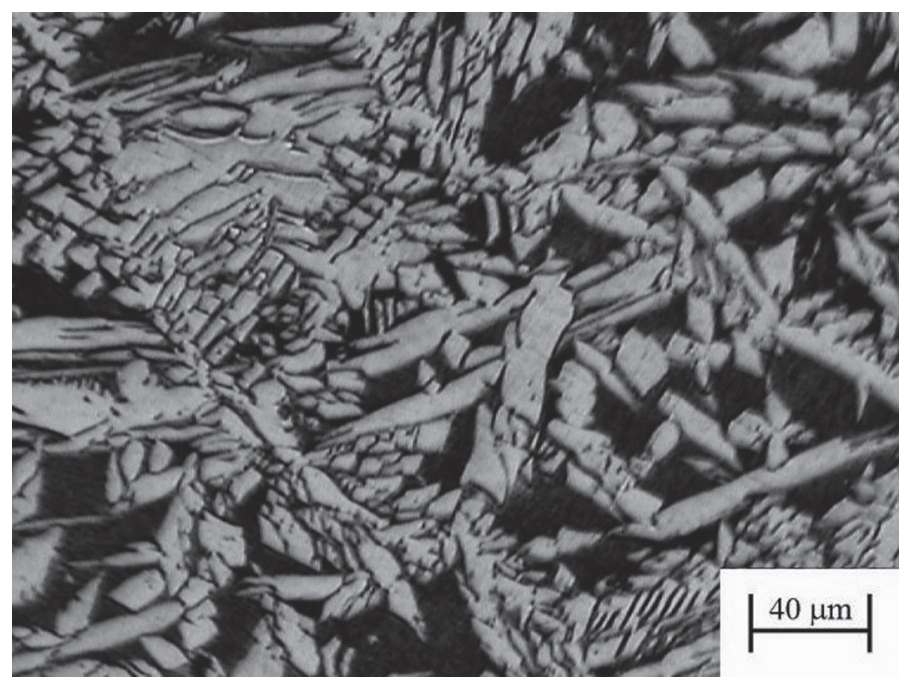

Figura 14. Microestrutura do MS na raiz da junta. Amostra 4.

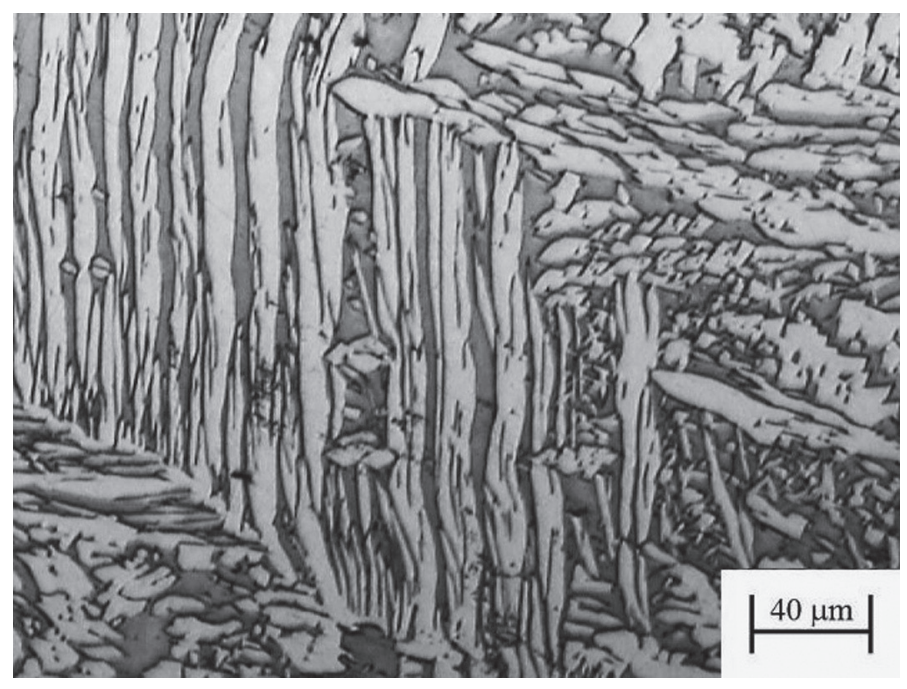

Figura 15. Microestrutura do MS na raiz da junta. Amostra 5.

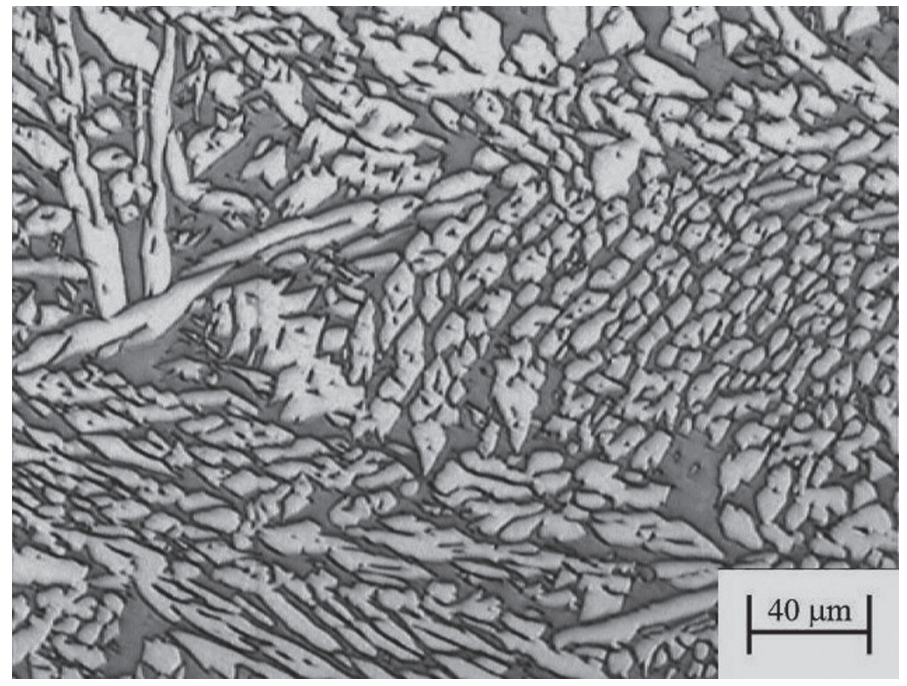

Figura 16. Microestrutura do MS na raiz da junta. Amostra 6.

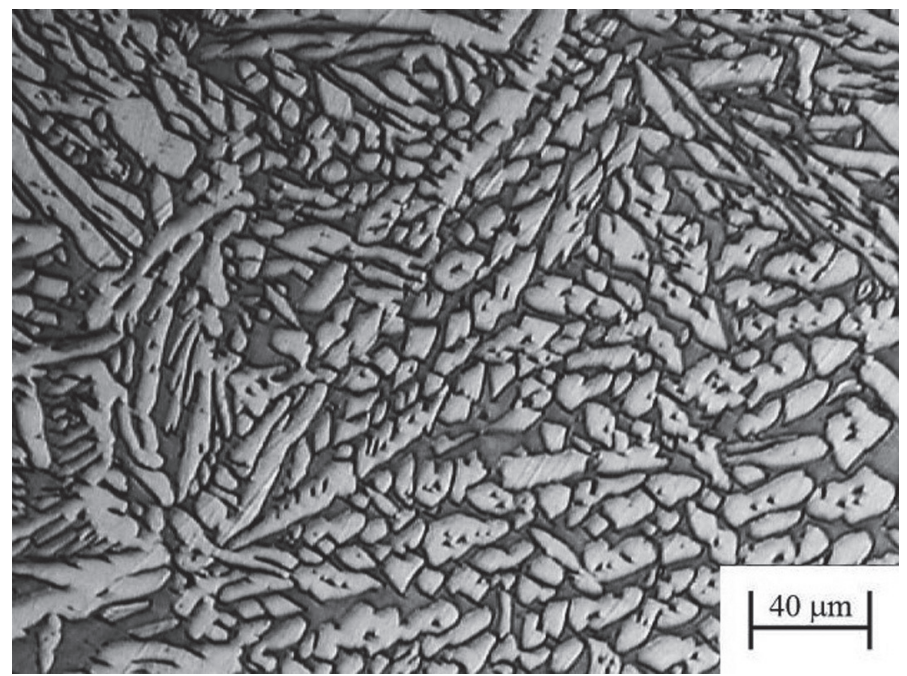

Figura 17. Microestrutura do MS na raiz da junta. Amostra 7.

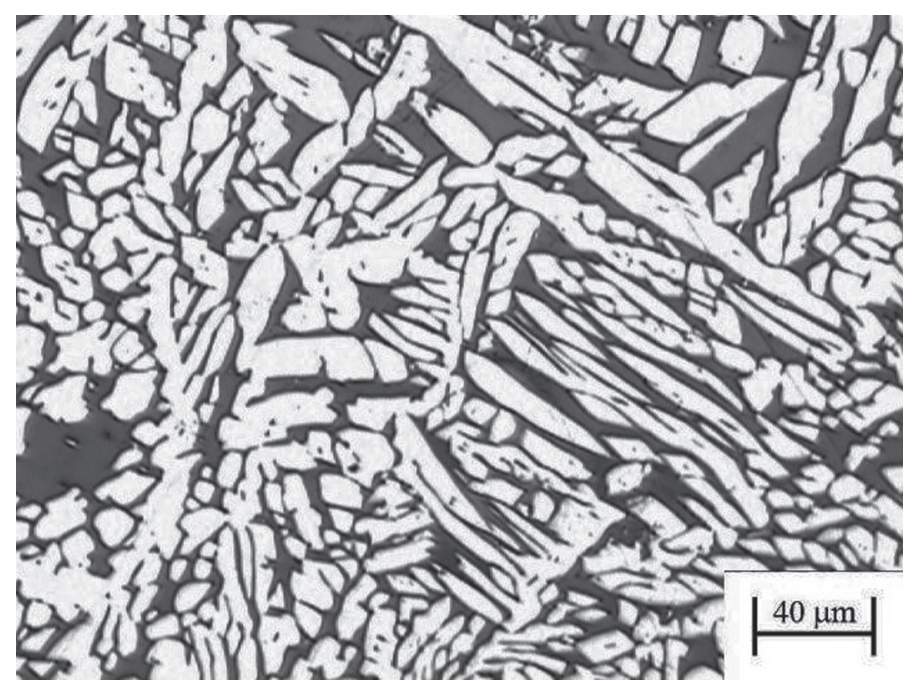

Figura 18. Microestrutura do MS na raiz da junta. Amostra 8. 
(a)

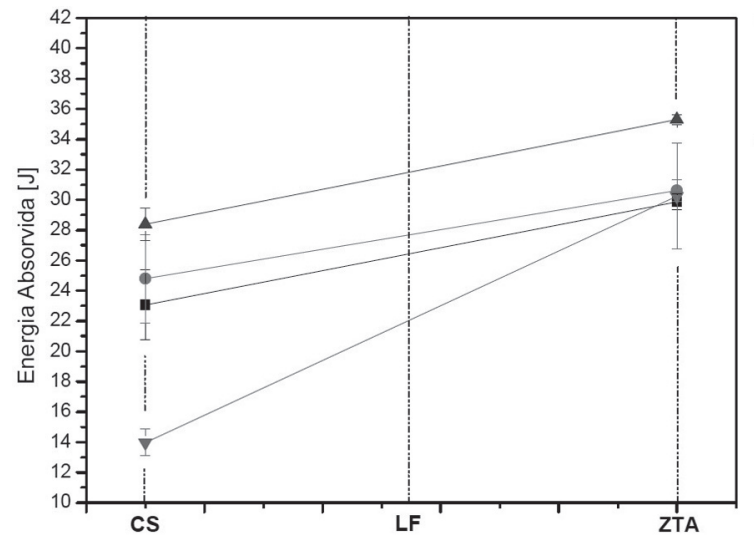

(b)

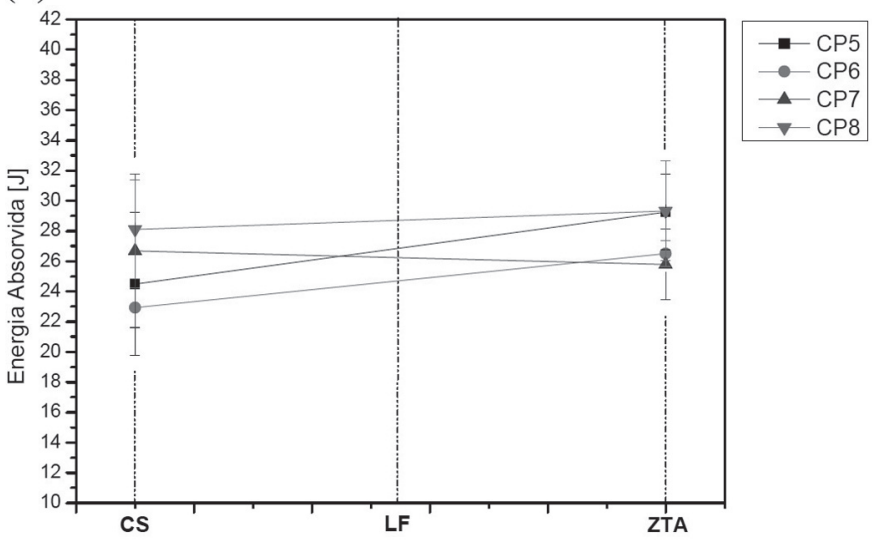

Figura 19. Tenacidade na raiz da junta soldada. (a) Cps de 1 a 4. (b) Cps de 5 a 8.

(a)

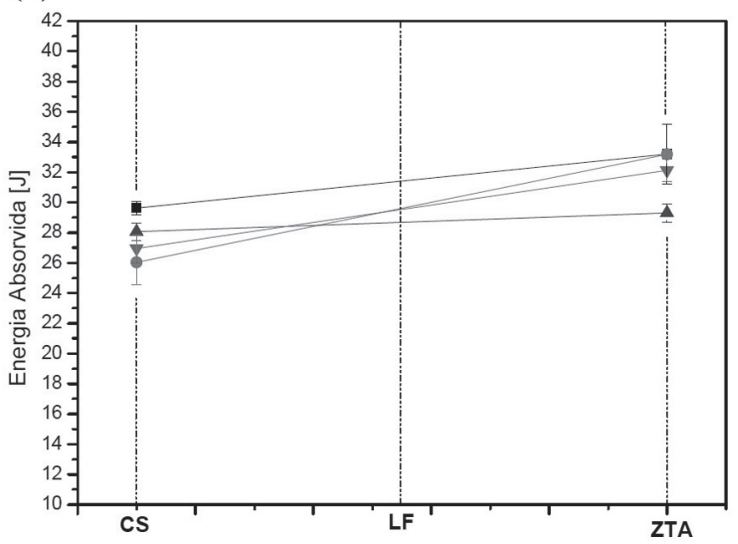

(b)

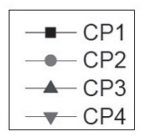

Figura 20. Tenacidade no enchimento da junta soldada. (a) Cps de 1 a 4. (b) Cps de 5 a 8.

Tabela 6. Proporção de fases na raiz e no metal de base.

\begin{tabular}{c|c|c}
\hline \multirow{2}{*}{ Amostra } & \multicolumn{2}{|c}{ Proporção de Fases (\%) } \\
\cline { 2 - 3 } & Ferrita $(\boldsymbol{\delta})$ & Austenita $(\gamma)$ \\
\hline MB & $46,69 \pm 1,90$ & $53,31 \pm 1,90$ \\
\hline $\mathbf{1}$ & $45,93 \pm 1,78$ & $54,07 \pm 1,78$ \\
\hline $\mathbf{2}$ & $51,62 \pm 2,30$ & $48,38 \pm 2,30$ \\
\hline $\mathbf{3}$ & $50,15 \pm 4,52$ & $49,85 \pm 4,52$ \\
\hline $\mathbf{4}$ & $44,66 \pm 2,19$ & $55,34 \pm 2,19$ \\
\hline $\mathbf{5}$ & $44,52 \pm 2,19$ & $55,48 \pm 2,19$ \\
\hline $\mathbf{6}$ & $48,01 \pm 2,44$ & $51,99 \pm 2,44$ \\
\hline $\mathbf{7}$ & $50,02 \pm 3,10$ & $49,98 \pm 3,10$ \\
\hline $\mathbf{8}$ & $47,25 \pm 3,19$ & $52,75 \pm 3,19$ \\
\hline
\end{tabular}

As Figuras 19 (a) e (b) exibem os valores de tenacidade levantados na raiz para o CS e ZTA nos cps $1-4$ e 5-8, respectivamente.

As Figuras 20 (a) e (b) mostram os valores de tenacidade obtidos no enchimento para o CS e ZTA nos cps 1-4 e 5-8, respectivamente. Assim como no caso da raiz, todas as fraturas foram dúcteis. Salienta-se ainda que, de forma geral, os valores obtidos no enchimento foram quase semelhantes aos obtidos na raiz.
Cabe destacar que todos os cps apresentaram claros sinais de deformação plástica, sendo estes medidos a partir da expansão lateral com o auxilio de um paquímetro. Como era de esperar o cp 4 (CS raiz), cuja superfície de fratura é mostrada na Figura 21 , foi o que apresentou menor expansão lateral (23\%).



Figura 21. Superfície de fratura do cp 4 (CS raiz) após teste de impacto Charpy, mostrando a expansão lateral. 
Tendo em vista que os cps ensaiados foram de tamanho reduzido, a relação entre a energia absorvida para cps convencionais $(55 \mathrm{~mm} \times 10 \mathrm{~mm} \times 10 \mathrm{~mm})$ e de tamanho reduzido é considerado pela norma ASTM A370 [8]. Segundo a NORSOK M601 [2] o valor de energia mínima absorvida, para a classe Duplex $25 \mathrm{Cr}$, é de $27 \mathrm{~J}$ à temperatura de $-46^{\circ} \mathrm{C}$ para cps convencionais. Segundo a ASTM A370 [8], o valor corrigido de energia para cp de tamanho reduzido de $2,5 \mathrm{~mm}$ é de 7 J. Portanto, o cp 4 (CS raiz) apresentou um valor de energia absorvida (14 J) acima da mínima estabelecida.

Deste modo, pode-se verificar que não houve influência do gás de proteção e aporte calor nos valores de tenacidade levantados na raiz. Por outra parte, evidenciou-se, um aumento do valor da tenacidade na região da ZTA se comparada com o CS a exceção do CP7, tal comportamento foi também reportado recentemente por Pardal et al. [9].

Outro aspecto interessante, que resulta dos valores obtidos no ensaio de impacto, é atribuído à influencia do oxigênio presente na microestrutura em decorrência da não utilização de gás de purga. Neste trabalho, como os valores levantados de tenacidade foram elevados e todas as fraturas foram dúcteis, induz a dizer que o teor de oxigênio na raiz de juntas não protegidas totalmente não influenciou nos valores obtidos de tenacidade.

\section{Conclusões}

O presente trabalho teve como principal objetivo a avaliação da influência da utilização de gás de purga com diferentes níveis de proteção gasosa e aporte de calor em juntas soldadas pelo processo GTAW em tubos de aço inoxidável superduplex UNS S32750, permitindo obter as seguintes conclusões:

1) Não se evidenciou uma influência significativa do grau de proteção e do aporte de calor na proporção de fases precipitadas. As proporções de fases ferrita e austenita são compráveis ao MB em todos os casos.

2) Os valores de tenacidade mostram valores próximos entre os cps ensaiados para a raiz e o enchimento, não mostrando influência significativa do nível de proteção de gás de purga e aporte de calor.

3) Embora fenômenos de oxidação superficial possam ocorrer, estes não acarretam em efeitos negativos para microestrutura. Nas condições estudadas, para aportes de calor da ordem de $0,5 \mathrm{~kJ} / \mathrm{mm}$, recomenda-se como limite de proteção gasosa na raiz até $3^{\text {a }}$ camada tendo em vista da temperatura de pico estar próxima dos $700^{\circ} \mathrm{C}$ e teor de nitrogênio próximo do valor do MB. No entanto, para aportes de calor na ordem de 1,5 $\mathrm{kJ} / \mathrm{mm}$, o limite de proteção gasosa na raiz deve ser realizado até a $4^{\text {a }}$ camada. Vale salientar, que após a soldagem, uma passivação decapante da junta deverá ser realizada em todos os casos.

\section{Agradecimentos}

Os autores agradecem à Empresa UTC Engenharia pelo valioso suporte na realização deste trabalho, ao $\mathrm{CNPq}$ e à FAPERJ, pelo suporte financeiro e ao Eng. Talles Montenegro, pelo apoio no desenvolvimento deste trabalho.

\section{Referências Bibliográficas}

[1] GUNN, R.N., 2003. "Duplex stainless steels. Microstructure, properties and applications". Cambridge - England: Abington Publishing. 204 p.

[2] NORSOK STANDARD M-601, 2004: "Welding and Inspection of Piping”. Rev. 4.

[3] IMOA - INTERNATIONAL MOLYBDENIUM ASSOCIATION, 2009. "Practical guidelines for the fabrication of duplex stainless steels". London - England, 63 p. 10 Out. 2012, <http://www.imoa.info/_files/stainless_steel/Duplex Stainless_Steel_2d_Edition.pdf $>$

[4] LIPPOLD, J.C.; KOTECKI, D.J. Welding metallurgy and weldability of stainless steels. John Wiley \& Sons, Inc, 2005.

[5] PARDAL, J.M., TAVARES, S.S.M.; FARIA, R.A., 2008 "Aços inoxidáveis Duplex (austeno-ferríticos) microestrutura e propriedades". Metalurgia \& Materiais; 64: 624-626.

[6] IMAGE TOOL Version 3.0, 2003. Department of Dental Diagnostic Science at The University of Texas Health Science Center (UTHSCSA), San Antonio, Texas. 10 Out. $2012<$ http:// compdent.uthscsa.edu/dig/itdesc.html $>$.

[7] ASTM E 23-05: "Standard Test Methods for Notched Bar Impact Testing of Metallic Materials".

[8] ASTM A 370-08: "Standard Test Methods and Definitions for Mechanical Testing of Steel Products".

[9] PARDAL, J. M.; SOUZA, G. C.; TAVARES, S. S. M., FONSECA, M. P. C., RIBEIRO, L. R., MARTINS, L. M.; FILHO, O. A.S., 2011 "Caracterização e Avaliação da Resistência à Corrosão na Soldagem de Tubulação de Aço Inoxidável Duplex UNS S31803 pelo Processo a Arco Submerso". Soldagem e Inspeção; Volume 16, № 4. 